\title{
How an augmented reality game (Pokémon GO) affected volunteer contributions to OpenStreetMap
}

\author{
Brian Alan Johnson ${ }^{\mathrm{a}, *}$ \\ ${ }^{a}$ Natural Resources and Ecosystem Services Area, Institute for Global Environmental Strategies, Japan, johnson@iges.or.jp \\ * Corresponding author
}

\begin{abstract}
OpenStreetMap (OSM) has become one of the largest sources of volunteered geographic information (VGI), and the data is now used for a wide range of applications. A massively popular augmented reality game, Pokémon GO, recently adopted OSM data for its in-game map and many of its in-game mechanics. This study investigated: (1) How Pokémon GO affected the quantity of daily contributors and daily edits to OSM in South Korea (the only country where OSM data was used exclusively since the game's launch); and (2) How the game affected volunteers' contribution habits. The main findings were: (i) the number of daily contributors and daily edits both increased by more than 17 times following the launch of Pokémon GO in South Korea, but returned to more normal levels after around 11/2 months; (ii) Most individuals contributing to OSM because of Pokémon GO reportedly did so to improve the in-game map appearance and in-game mechanics; and (iii) Individuals motivated to contribute to OSM because of Pokémon GO tended to create/edit OSM "park" and "water body" features more than other OSM contributors. It is notable that the large increases in OSM contributors and edits occurred even in the absence of any formal guidance or encouragement by the game operator or other parties. If greater efforts are made to encourage participation in VGI initiatives linked to AR games, the observed impacts will likely be even more dramatic.
\end{abstract}

Keywords: volunteered geographic information, crowdsourced geographic data, OSM, mobile gaming

\section{Introduction}

OpenStreetMap (OSM) is one of the largest sources of volunteered geographic information (VGI) worldwide (Neis and Zielstra, 2014), and OSM data is now being used for many applications including transportation routing (Luxen and Vetter, 2011), land use/land cover mapping (Estima and Painho, 2013; Johnson et al., 2017; Johnson and Iizuka, 2016), disaster preparation/response (Soden and Palen, 2014), population downscaling (Bakillah et al., 2014), spatial accessibility analysis (Johnson et al., 2019), and tree crown delineation (Vahidi et al., 2018). VGI is typically contributed by citizen volunteers through remote mapping operations (e.g. manual digitizing of points/lines/polygons onto georeferenced satellite imagery) or in-situ data collection/generation using a mobile device with GPS capabilities (e.g. a smartphone) (Vahidi et al., 2018). Notably, the citizen volunteers usually do not receive any kind of payment for the data they contribute.

The factors that motivate individuals to contribute to VGI initiatives like OSM can vary widely (Coleman et al., 2009), and volunteers' contribution patterns - e.g. the types and quantity of map features that they create/edit often differ according to their motivations for contributing (Neis and Zipf, 2012). For example, the incorporation of VGI into an augmented reality (AR) game may motivate the game's players to become new contributors to a VGI project, and/or change the habits of new/existing contributors. This study investigates how a popular AR game, Pokémon GO, affected volunteer contributions to the OSM initiative.

\subsection{Pokémon GO and OSM}

Pokémon GO employs geospatial data for its in-game map and many of its in-game mechanics. For example, the types of "Pokémon" (fictional monsters) that appear at a specific location are influenced by the geographic features present at that location; e.g. aquatic Pokémon appear more frequently near water bodies. At the time of the game's initial launch, a non-VGI dataset (Google Maps) was generally used for these purposes. VGI (OSM) data was used only in South Korea, and this was due to the country's security regulations prohibiting the provisioning of commercial GIS data to non-Korean companies (including Google). Starting in November 2017, however, OSM replaced Google Maps as the game's principal source of map data in all other countries as well. After adopting OSM, the game operator (Niantic, Inc.) did not provide any form of guidance to players on how to contribute to OSM to improve the game's playability. For this reason, players got together and made their own discoveries through crowdsourced research activities conducted on online discussion boards (e.g. https://www.reddit.com/r/TheSilphRoad/). Based on the crowdsourced research, the types of OSM "tags" that affected the in-game mechanics were identified, and player-created guides for contributing to OSM were developed (e.g. https://pokemongo.gamepress.gg/basicguide-open-street-maps). 
It is likely that the adoption of OSM in Pokémon GO led to many new OSM contributors, and may also have affected the contributing habits of the new (and existing) OSM contributors. The motivations for the current study were thus to investigate: (1) How the adoption of OSM data in Pokémon GO affected citizen participation in OSM, in terms of the number of daily contributors (\#contributors) and the number of nodes created per day (\#edits) in South Korea; and (2) How volunteers' contribution habits were affected by the game, in terms of the types of OSM map features individuals were motivated to create/edit, where, and why.

\section{Methods}

\subsection{Time-series analysis of \#contributors and \#edits}

To evaluate how the number of OSM contributors (\#contributors) and the quantity of map features created/edited (\#edits) were affected by Pokémon GO, I conducted a time-series analysis of the \#contributors and \#edits per day in South Korea prior to and following the game's launch. South Korea was selected for this analysis because it is a country with millions of active gamers and the only country where OSM data was used exclusively since the game's launch (the time of the game's peak popularity). The impacts of the game's adoption of OSM data, if significant, should thus be quite evident for this country. Pokémon GO was released in South Korea on January 24, 2017, so for time-series analysis, the values of \#contributors and \#edits were retrieved for January 10March 10, 2017 from OSMstats (https://osmstats.neisone.org/).

\subsection{Questionnaire of OSM contribution habits}

Next, to get an understanding of how the game affected volunteers' contributing habits and motivations, an online questionnaire was posted on a popular Pokémon GO discussion board (https://www.reddit.com/r/TheSilphRoad/). In this questionnaire, I asked the types of map features volunteers tended to create/edit most frequently, and if/how the game affected their contribution habits. Table 1 shows the relevant questions from the questionnaire for this study. To determine if the OSM contribution habits of those individuals primarily motivated to contribute because of Pokémon GO significantly differed from the habits of other individuals (i.e. those not motivated to contribute to OSM because of Pokémon GO), paired sample T-tests (Mee and Chua, 2018) were used.

\section{Results and Discussion}

\subsection{Time-series analysis of \#contributors and \#edits}

In South Korea, the \#contributors and \#edits to OSM per day both increased more than 10-fold immediately following the launch of Pokémon GO (Figure 1). In the two weeks prior to the game's release, the average \#contributors was 15 and the average \#edits was 4,028. In comparison, in the week following release, the average \#contributors (584) was 40-times higher and the average \#edits $(70,345)$ was 17-times higher. However, both \#contributors and \#edits returned to more typical levels after around $1 \frac{1}{2}$ months. One explanation for this drop-off is that the new contributors had finished mapping the locations where they frequently played the game. Another explanation could be that, because edits made in OSM often take a significant amount of time (several months) to be incorporated into the game, many of the new OSM contributors may have lost interest when no immediate results were observed. From these results, it was interpreted that Pokémon GO had a major short-term impact on the number of users and number of edits in OSM, but the majority of the new contributors quickly lost interest in the mapping because their motivation was mainly just to improve their gameplay experience. Despite the short time period over which the increased volunteer contributions occurred, the result was still over 1 million additional OSM edits, as can be seen in Figure 1.

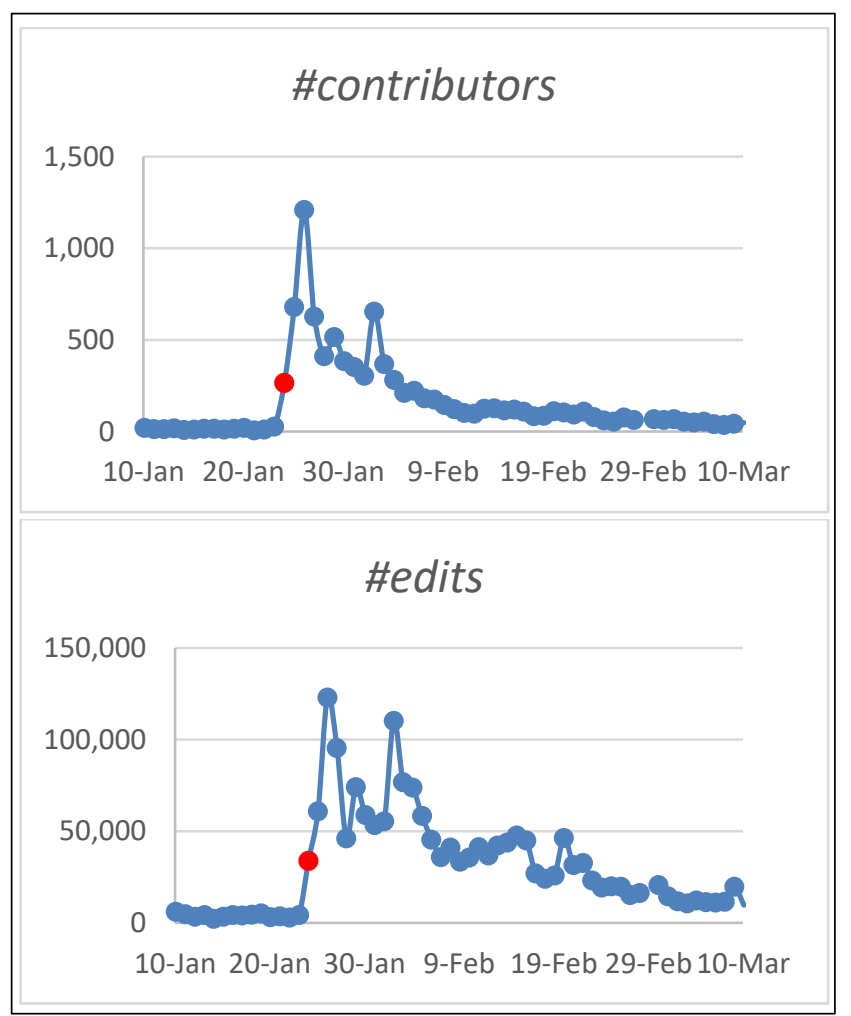

Figure 1. \#contributors (top) and \#edits (bottom) to OSM in South Korea, prior to and following the launch of Pokémon GO on January 24, 2017 (indicated by the red dot).

\subsection{Questionnaire of OSM contribution habits}

The main findings from the online questionnaire - shown in detail in Tables 1 and 2 - were:

a) Most respondents lived in North America and Western Europe, probably because this was an English language questionnaire posted on an English language discussion board;

b) Most of the respondents were primarily motivated to contribute to OSM because of Pokémon $\mathrm{GO}$, which is as expected because the questionnaire was posted on a Pokémon GO discussion board; 
c) Most contributors wanted to improve both the ingame map appearance as well as increase/improve/change the Pokémon that appear at the mapped locations; and

d) Individuals motivated to contribute to OSM primarily because of Pokémon GO tended to create/edit Water bodies (e.g. rivers, lakes, ponds, or swimming pools) and Parks (or other green spaces) more frequently than other individuals, and the result was statistically significant at $\mathrm{p}<0.05$. For other OSM map features, the difference between the two groups was not statistically significant.

\begin{tabular}{|c|c|}
\hline Question & Answers (\# of responses) \\
\hline $\begin{array}{l}\text { In what region do you } \\
\text { live? }\end{array}$ & $\begin{array}{l}\text { North America (185), } \\
\text { Western Europe (130), } \\
\text { Eastern Europe (33), Oceania } \\
\text { (16), South America (16), } \\
\text { East Asia (7), South Asia (4), } \\
\text { Southeast Asia (4), Central } \\
\text { Asia (4), Africa (2) }\end{array}$ \\
\hline $\begin{array}{l}\text { Are you primarily } \\
\text { motivated to } \\
\text { contribute to } \\
\text { OpenStreetMap } \\
\text { primarily because of } \\
\text { Pokémon GO? }\end{array}$ & Yes (353), No (54) \\
\hline $\begin{array}{l}\text { What is your } \\
\text { motivation } \\
\text { for contributing to } \\
\text { OpenStreetMap in } \\
\text { regards to Pokemon } \\
\text { Go? (check all that } \\
\text { apply) }\end{array}$ & $\begin{array}{l}\text { I want to improve the map } \\
\text { appearance in Pokemon Go } \\
\text { at the locations ( } 317) \text {, I want } \\
\text { to increase/improve/change } \\
\text { the Pokemon that could be } \\
\text { encountered at these } \\
\text { locations (257), Other (43). }\end{array}$ \\
\hline $\begin{array}{l}\text { What types of } \\
\text { OpenStreetMap featur } \\
\text { es to you frequently } \\
\text { create/edit? }\end{array}$ & $\begin{array}{l}\text { Parks or other public green } \\
\text { spaces (292), Other types of } \\
\text { paths (e.g. footpaths) (274), } \\
\text { Buildings (249), Buildings } \\
\text { (249), Roads (212), Water } \\
\text { bodies (203), Points of } \\
\text { Interest (163), Land use } \\
\text { zones (118), Forests and } \\
\text { other areas with natural } \\
\text { vegetation (104), } \\
\text { Agricultural areas (30) }\end{array}$ \\
\hline
\end{tabular}

Table 1. Questions and answers of online questionnaire.

The most interesting result of this questionnaire was that individuals motivated to contribute to OSM because of Pokémon GO were more likely to frequently create/edit OSM "Water body" and "Park" map features. This was likely due to the fact that these features have significant impacts on the in-game mechanics. For example, aquatic Pokémon appear much more frequently near water bodies, so players in areas without existing OSM water body features were likely highly motivated to digitize all of the water bodies at the locations where they play to ensure that they can encounter these types of Pokémon. In addition, there are often Pokémon "nests" (i.e. areas with many Pokémon and/or unique Pokémon) located in parks (https://pokemongo.gamepress.gg/basic-guide-openstreet-maps), so players were also likely motivated to ensure that all of the parks were mapped in the locations that they frequently played the game.

\begin{tabular}{|l|l|l|}
\hline $\begin{array}{l}\text { Primarily motivated to contribute } \\
\text { to OpenStreetMap primarily } \\
\text { because of Pokemon Go? }\end{array}$ & $\begin{array}{l}\text { Yes } \\
(n=353)\end{array}$ & $\begin{array}{l}\text { No } \\
(n=54)\end{array}$ \\
\hline $\begin{array}{l}\text { Frequently create/edit: } \\
\text { Roads }\end{array}$ & $34 \%$ & $36 \%$ \\
$\begin{array}{l}\text { Other types of paths (footpaths, } \\
\text { etc.) }\end{array}$ & $59 \%$ & $67 \%$ \\
$\begin{array}{l}\text { Buildings } \\
\text { Water bodies }\end{array}$ & $39 \%$ & $33 \%$ \\
$\begin{array}{l}\text { Parks or other public green spaces } \\
\text { Forests or other areas of natural } \\
\text { vegetation }\end{array}$ & $\mathbf{7 1 \%}$ & $\mathbf{4 7 \%}$ \\
$\begin{array}{l}\text { Agricultural areas } \\
\text { Land use zones (e.g. residential, } \\
\text { industrial, or commercial areas) }\end{array}$ & $16 \%$ \\
$\begin{array}{l}\text { Points of interest (e.g. landmarks } \\
\text { or other interesting/important } \\
\text { objects) }\end{array}$ & $\mathbf{5 4 \% *}$ & $23 \%$ \\
\hline
\end{tabular}

Table 2. OSM contribution habits. *Difference between the two groups statistically significant at $\mathrm{p}<0.05$.

\section{Conclusions}

This study investigated how Pokémon GO affected volunteer contributions to OpenStreetMap. For this, I first analysed the number of daily contributors and number of daily edits to OpenStreetMap in South Korea, before and after the game's release. This time-series analysis showed that the both the number of contributors and the number of edits increased drastically after the game's launch, but only for a short time period ( $\sim 1 / 2$ months). I also conducted an online survey to understand how the game affected volunteers' data contribution habits, and found that those OpenStreetMap contributors that were motivated primarily by the game tended to add data related to water bodies and parks more than other volunteers. Further work could investigate how Pokémon GO affected the quantity of contributors/edits in other countries besides South Korea, or on how other augmented reality games have affected OpenStreetMap and other volunteered geographic information initiatives.

\section{References}

Bakillah, M., Liang, S., Mobasheri, A., Jokar Arsanjani, J., Zipf, A., 2014. Fine-resolution population mapping using OpenStreetMap points-of-interest. Int. J. Geogr. 
Inf. Sci. 28, 1940-1963.

Coleman, D.J., Georgiadou, Y., Labonte, J., 2009. Volunteered Geographic Information: The nature and motivation of produsers. Int. J. Spat. Data Infrastructures Res. 4, 332-358. https://doi.org/10.2902/17250463.2009.04.art16

Estima, J., Painho, M., 2013. Exploratory Analysis of OpenStreetMap for Land Use Classification. Proc. Second ACM SIGSPATIAL Int. Work. Crowdsourced Volunt. Geogr. Inf. 39-46.

Johnson, B.A., Dasgupta, R., Hashimoto, S., Kumar, P., Onishi, A., 2019. Integrating spatial accessibility estimates derived from crowdsourced, commercial, and authoritative geo-datasets: Case study of mapping accessibility to urban green space in the TokyoYokohama area. Proc. Int. Cartogr. Assoc.

Johnson, B.A., Iizuka, K., 2016. Integrating OpenStreetMap volunteered geographic information and Landsat time-series imagery for rapid land use/land cover (LULC) mapping: Case study in the Laguna de Bay area of the Philippines. Appl. Geogr. 67, 140-149.

Johnson, B.A., Iizuka, K., Bragais, M.A., Endo, I., Magcale-Macandog, D.B., 2017. Employing crowdsourced geographic data and multitemporal/multi-sensor satellite imagery to monitor land cover change: A case study in an urbanizing region of the Philippines. Comput. Environ. Urban Syst. 64, 184-193. https://doi.org/10.1016/j.compenvurbsys.2017.02.002

Luxen, D., Vetter, C., 2011. Real-time routing with OpenStreetMap data, in: Proceedings of the 19th ACM SIGSPATIAL International Conference on Advances in Geographic Information Systems. ACM Press, New York, New York, USA, pp. 513-516.

Mee, R.W., Chua, T.I.N.C., 2018. Regression Toward the Mean and the Paired Sample t Test. Am. Stat. 45, 39-42.

Neis, P., Zielstra, D., 2014. Recent Developments and Future Trends in Volunteered Geographic Information Research: The Case of OpenStreetMap. Futur. Internet 6, 76-106.

Neis, P., Zipf, A., 2012. Analyzing the Contributor Activity of a Volunteered Geographic Information Project - The Case of OpenStreetMap. ISPRS Int. J. Geo-Information 1, 146-165.

Soden, R., Palen, L., 2014. From Crowdsourced Mapping to Community Mapping: The Post-earthquake Work of OpenStreetMap Haiti. COOP 2014 - Proc. 11th Int. Conf. Des. Coop. Syst. 27-30 May 2014, Nice 311-326. https://doi.org/10.1007/978-3-319-06498-7_19

Vahidi, H., Klinkenberg, B., Johnson, B.A., Moskal, L.M., Yan, W., 2018. Mapping the individual trees in urban orchards by incorporating Volunteered Geographic Information and very high resolution optical remotely sensed data: A template matching-based approach. Remote Sens. 10. https://doi.org/10.3390/rs10071134 